\title{
Effect of Laser Emission Parameters on Mechanical and Physical Properties of Cast Pure Titanium
}

\author{
Taro Hayashi, ${ }^{1}$ Ikuya Watanabe, ${ }^{2}$ Tadafumi Kurogi, ${ }^{1}$ \\ Takanobu Shiraishi, ${ }^{2}$ and Hiroshi Murata ${ }^{1}$ \\ ${ }^{1}$ Department of Prosthetic Dentistry, Graduate School of Biomedical Sciences, Nagasaki University, 1-7-1 Sakamoto, \\ Nagasaki 852-8588, Japan \\ ${ }^{2}$ Department of Dental and Biomedical Materials Science, Graduate School of Biomedical Sciences, Nagasaki University, \\ 1-7-1 Sakamoto, Nagasaki 852-8588, Japan
}

Correspondence should be addressed to Ikuya Watanabe; ikuyaw@nagasaki-u.ac.jp

Received 27 October 2014; Revised 10 December 2014; Accepted 10 December 2014; Published 24 December 2014

Academic Editor: Nikša Krstulović

Copyright (C) 2014 Taro Hayashi et al. This is an open access article distributed under the Creative Commons Attribution License, which permits unrestricted use, distribution, and reproduction in any medium, provided the original work is properly cited.

The objective of this study was to investigate the effect of laser beam parameters on the mechanical and physical properties of cast commercially pure titanium. Dumbbell-shaped test specimens (ISO6871) were cast with ASTM grades 2 and 3 Ti. The cast surfaces were laser-treated with various laser emission parameters (current: 200, 220, and 240 A; spot diameter: 1.0, 1.6 mm; pulse duration: $10,1 \mathrm{~ms}$ ) under argon shielding. Tensile testing was conducted at a crosshead speed of $1.0 \mathrm{~mm} / \mathrm{min}$. Data of tensile strength and elongation were statistically analyzed using ANOVA/Tukey's test $(\alpha=0.05)$. Hardness depth profiles were made with cross sections of rod-shaped specimens after laser treatments. Control specimens without laser treatment were also prepared. The laser-treated specimens showed significantly higher tensile strengths than those of control specimen for both grades 2 and 3 Ti. The specimens treated with $1.0 \mathrm{~mm}$ spot diameter indicated higher tensile strengths than those treated with $1.6 \mathrm{~mm}$ spot diameter for both currents (200 A and $240 \mathrm{~A}$ ). The laser treatment decreased the subsurface hardness and increased the hardness between $75 \mu \mathrm{m}$ and $400 \mu \mathrm{m}$ in depth when compared to the hardness of control specimens. Laser surface treatment for cast commercially pure titanium modified integrity of cast surface and significantly improved mechanical and physical property.

\section{Introduction}

Commercially pure (CP) titanium and its alloys have been widely applied for orthopedic and dental implants because of their excellent biocompatibility [1-3], high corrosion resistance $[4,5]$, inherent ability to osseointegrate, and low modulus of elasticity (Young's modulus) to more closely match to the elastic modulus of the bone $[3,6,7]$. The $\mathrm{CP}$ titanium is classified into four categories grades 1 through 4 depending on their varying degrees of tensile strength and hardness, as a function of oxygen content, with the grade 1 being the most ductile (lowest tensile strength and hardness with an oxygen content of $0.18 \%$ ) and grade 4 the least ductile (highest tensile strength and hardness with an oxygen content of $0.40 \%$ ) [8]. Even if the grade 4 pure titanium possesses highest strength and hardness, its strength and hardness are lower than those of titanium alloys, in which alloying elements modify microstructures resulting in improvement of their mechanical and physical properties. In dentistry, the $\mathrm{CP}$ titanium and its alloys are cast to fabricate metal framework for individual patient's demand [9-15]. Since titanium has extremely high affinity with oxygen at high temperature, cast titanium surfaces are usually contaminated with refractory oxide contained in the investment material during casting. The contaminated surface layers reduce the integrity of cast surface and induce hard and brittle cast surfaces which lead to decrease in mechanical properties [16], fatigue [17], and wear resistances [18].

Metal peening is one of the methods to enhance mechanical property and fatigue resistance of metal materials and has been applied in industry [19-21]. The process of peening metal's surface, which is normally cold work, includes 
mechanical means such as hammer blows and blasting with shot (shot peening). Mechanical peening expands the surface of the cold metal, introducing residual compressive stresses $[19,20]$ and relieving the tensile stresses that are already present, and also encourages strain hardening of the surface metal [21]. The residual compressive stresses in a peened surface and tensile stresses in the interior are induced by plastic deformation of the metal surfaces and increase fatigue and corrosion resistances of the peened materials. Another peening method to increase mechanical properties and fatigue resistance is laser peening. Laser beams are widely used for enhancement of metal surfaces by modifying the surface microstructure into specific phases such as metastable phase and nanocrystalline grain phase [22-29]. Laser surface melting of metallic materials should be undergone in controlled inert gas atmosphere of argon or helium, particularly for titanium, in order to shield it from contamination with atmospheric gasses such as oxygen, nitrogen, or hydrogen since the contamination of titanium surface reduces integrity of surface microstructure resulting in decrease of mechanical properties. Microstructure of titanium surface is also affected by heating temperature, holding time, and cooling rate of the substrates; therefore the laser melting parameters should be optimized in order to reduce defects and to optimize microstructure [30]. Morphology of the layers created and nature of the phases formed on surface mostly depend on the laser beam overlapping [31] and the intensity of laser beam $[27,32]$ and nature of surrounding gas $[24,25,27,29]$.

In previous studies, laser treatment on cast titanium surfaces could produce reliable titanium metal frameworks for dental prostheses since significant enhancement of their mechanical properties can be obtained by laser treatment [33, 34]. Therefore, the objective of this study was to investigate the effect of laser beam parameters (out-put current, spot diameter, and pulse duration) on the mechanical and physical properties of cast commercially pure titanium.

\section{Materials and Methods}

2.1. Preparation of Specimens. Two types of commercially pure titanium (CP-Ti) were used in this study: ASTM grade 2 (T-alloy M, GC Corp., Tokyo, Japan) and grade 3 (Talloy H, GC Corp.) pure titanium ingots. Dumbbell-shaped patterns (Figure 1: ISO6871, $18 \mathrm{~mm}$ for gauge length, $3 \mathrm{~mm}$ in diameter) and rod patterns $(8 \mathrm{~mm}$ length and $3 \mathrm{~mm}$ in diameter) were prepared for casting of the CP-Ti. The CP-Ti was cast with a magnesia-based investment material (Selevest CB, Selec Co., Osaka, Japan) using an argon-arc melting/ centrifugal titanium casting machine (Ticast Super R, Selec Co.). After casting, the molds were bench-cooled to room temperature and the cast specimens were retrieved. The surfaces of the cast specimens were air-abraded with $50 \mu \mathrm{m}$ $\mathrm{Al}_{2} \mathrm{O}_{3}$ particles to uniform surface conditions. The specimens were then ultrasonically cleaned with acetone for $10 \mathrm{~min}$.

2.2. Laser Surface Treatment. Laser surface treatment was applied using a dental Nd:YAG laser welding machine (Tanaka TLL-7000, Homburg, Germany) using the parameters as

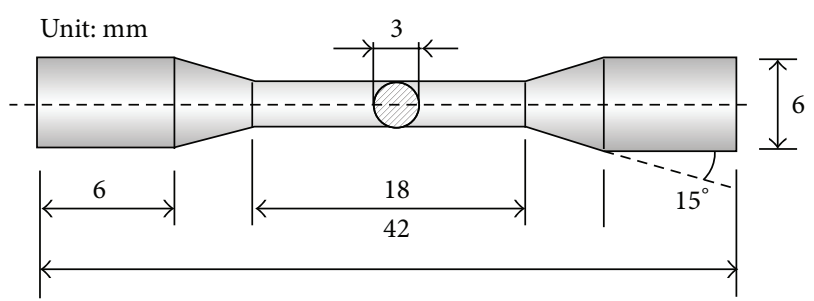

FIGURE 1: Schematic illustration of dumbbell-shaped tensile specimen (ISO6871).

TABLE 1: Laser emission parameters used in this study.

\begin{tabular}{lccc}
\hline Condition & Current (A) & $\begin{array}{c}\text { Pulse duration } \\
(\mathrm{ms})\end{array}$ & $\begin{array}{c}\text { Spot diameter } \\
(\mathrm{mm})\end{array}$ \\
\hline 1 & 200 & 10 & 1.0 \\
2 & 200 & 10 & 1.6 \\
3 & 220 & 10 & 1.0 \\
4 & 220 & 1 & 1.0 \\
5 & 240 & 10 & 1.0 \\
6 & 240 & 10 & 1.6 \\
\hline
\end{tabular}

shown in Table 1 . The parameters (current of $240 \mathrm{~A}$, pulse duration of $10 \mathrm{~ms}$, and spot diameter of $1.0 \mathrm{~mm}$ ), which produce strongest laser pulse energy, were selected for laser to penetrate into cast and air-abraded titanium surface with $0.8-1.0 \mathrm{~mm}$ in depth [35]. During the laser surface treatment, argon gas shielding was applied from two nozzles set at a 45degree angle on both sides above the treatment area of the specimen. Single-pulsed laser was shot perpendicular to the long axis of each specimen in order to avoid misshaping of the straight gauge due to the induction of compressive stresses induced by laser. The laser pulses were applied to whole gauge surfaces including up to $3 \mathrm{~mm}$ of the gripping surfaces and were $50 \%$ overlapped to ensure the entire testable surfaces as shown in Figure 2. The specimens without laser treatment were prepared as controls.

2.3. Tensile Testing and SEM Observation. Tensile testing was conducted using a universal testing machine (Model, Instron Corp., Canton, MA) at a crosshead speed of $1.0 \mathrm{~mm} / \mathrm{min}$. Tensile strength $(\mathrm{MPa})$ and percent elongation (elongation with total extension at break) were recorded. The data $(n=3)$ were statistically analyzed using ANOVA and Tukey's test at a significant level of $\alpha=0.05$. After tensile testing, the fracture surfaces were observed using a scanning electron microscope (SEM).

2.4. Hardness Depth Profiling. Hardness depth profiles were made on the cross-sectioned surfaces of the rod-shaped specimens after the cast rods underwent the same laser treatments. Vickers' hardness depth-profiles include measurements at $25 \mu \mathrm{m}$ from cast surface to $1,000 \mu \mathrm{m}$ in depth with $25 \mu \mathrm{m}$ increments up to $100 \mu \mathrm{m}$ and $50 \mu \mathrm{m}$ increments for $100-1,000 \mu \mathrm{m}$. Three measurements were averaged for each depth. The data were statistically analyzed by ANOVA and Tukey's test $(P<0.05)$. 


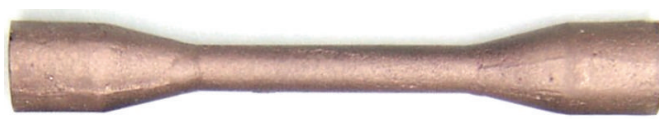

(a)

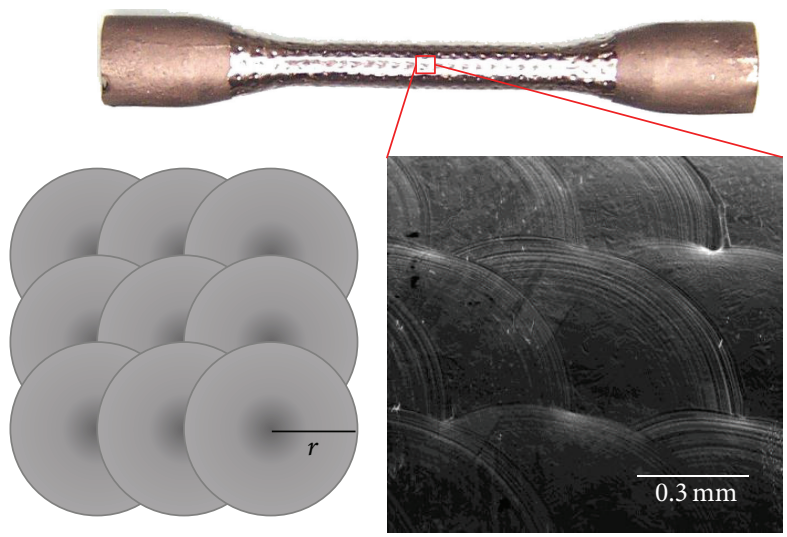

(b)

FIGURE 2: Schematic illustration of overlapped laser surface treatment: (a) control specimen after air-abrasion with $50 \mu \mathrm{m} \mathrm{Al}_{2} \mathrm{O}_{3}$ and $(\mathrm{b})$ laser-treated specimen; schematic illustration (bottom left, $r$ : radius of spot diameter) and SEM image (bottom right) of a specimen surface after laser treatment.

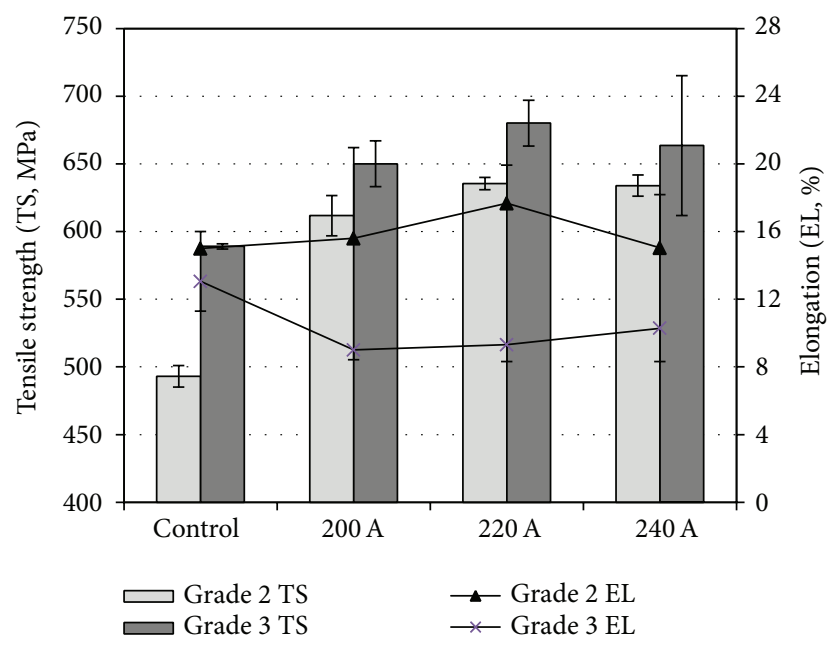

Figure 3: Tensile strengths and elongations of control specimens (grades 2 and 3) and the specimens laser-treated with several emission currents $(200 \mathrm{~A}, 220 \mathrm{~A}$, and $240 \mathrm{~A})$ at a constant pulse duration $(10 \mathrm{~ms})$ and a spot diameter $(1.0 \mathrm{~mm})$.

\section{Results}

3.1. Tensile Test Results. Tensile strengths and elongations of control specimens (grades 2 and 3 ) and the specimens lasertreated with various parameters (current, spot diameter, and pulse duration) for laser emission are presented in Figure 3 through Figure 6. When the specimens are laser-treated with three different currents (Figure 3), the laser treated specimens showed significantly higher tensile strengths than those of control specimen for both grades 2 and 3 pure titanium (Ti). The tensile strength increasing rate was much greater for grade $2 \mathrm{Ti}$ compared to grade $3 \mathrm{Ti}$. Increasing of current from $200 \mathrm{~A}$ to $220 \mathrm{~A}$ increased the tensile strengths of treated specimens for both $\mathrm{Ti}$ grades, thereafter the strength of the specimens treated at 240 A slightly decreased. The laser

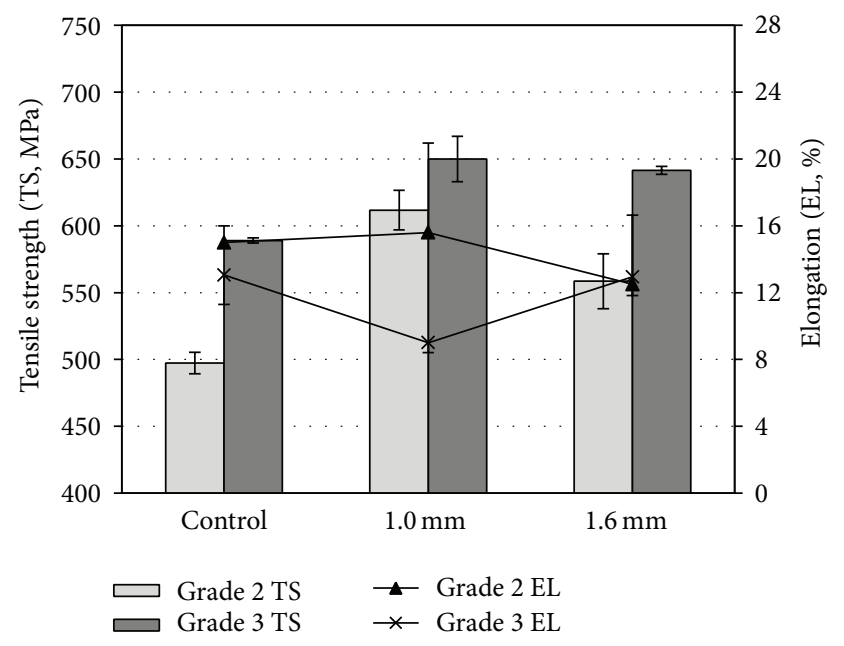

Figure 4: Tensile strengths and elongations of control specimens (grades 2 and 3) and specimens laser-treated with two different spot diameters $(1.0 \mathrm{~mm}$ and $1.6 \mathrm{~mm})$ at a constant emission current of $200 \mathrm{~A}$ and a pulse duration $(10 \mathrm{~ms})$.

treatment decreased the total elongation for grade $3 \mathrm{Ti}$, whereas it slightly increased the elongation of grade $2 \mathrm{Ti}$. The specimens laser-treated with two different spot diameters (1.0 $\mathrm{mm}$ and $1.6 \mathrm{~mm}$ ) also increased their tensile strengths for both $\mathrm{Ti}$ grades at a constant pulse duration $(10 \mathrm{~ms})$ with a current at either $200 \mathrm{~A}$ (Figure 4) or $240 \mathrm{~A}$ (Figure 5). The specimens laser-treated with $1.0 \mathrm{~mm}$ spot diameter indicated higher tensile strengths than those laser-treated with $1.6 \mathrm{~mm}$ spot diameter for both currents (200 A and $240 \mathrm{~A}$ ). The elongation was similar between control and $1.0 \mathrm{~mm}$ spot diameter for grade $2 \mathrm{Ti}$ and decreased at $1.6 \mathrm{~mm}$ spot diameter for both currents (Figures 4 and 5). The grade $3 \mathrm{Ti}$ decreased their elongations in order of control, $1.0 \mathrm{~mm}$ and $1.6 \mathrm{~mm}$ spot diameter except for $1.6 \mathrm{~mm}$ spot diameter at $200 \mathrm{~A}$ (Figure 4) which showed elongation similar to the control specimens. 


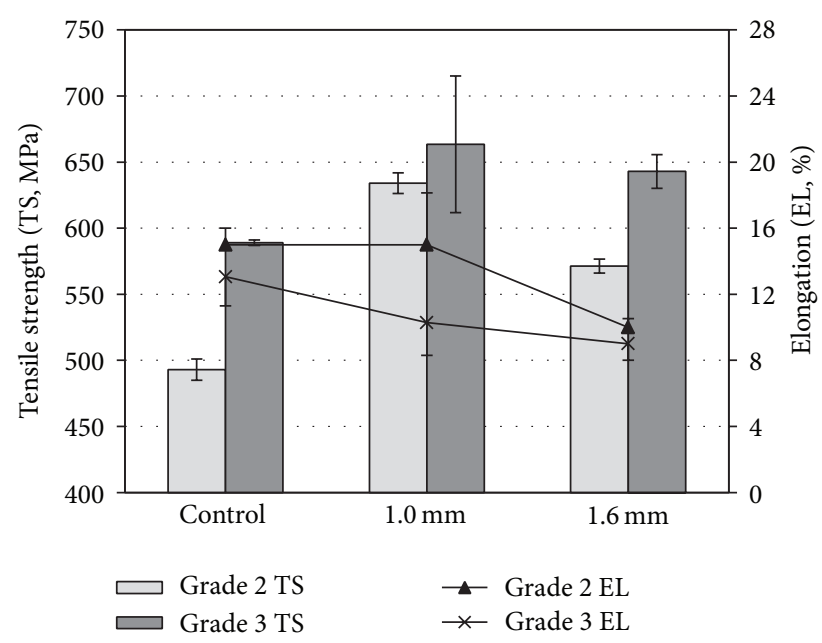

FIgURE 5: Tensile strengths and elongations of control specimens (grades 2 and 3) and specimens laser-treated with two different spot diameters $(1.0 \mathrm{~mm}$ and $1.6 \mathrm{~mm})$ at a constant emission current of $240 \mathrm{~A}$ and a pulse duration $(10 \mathrm{~ms})$.

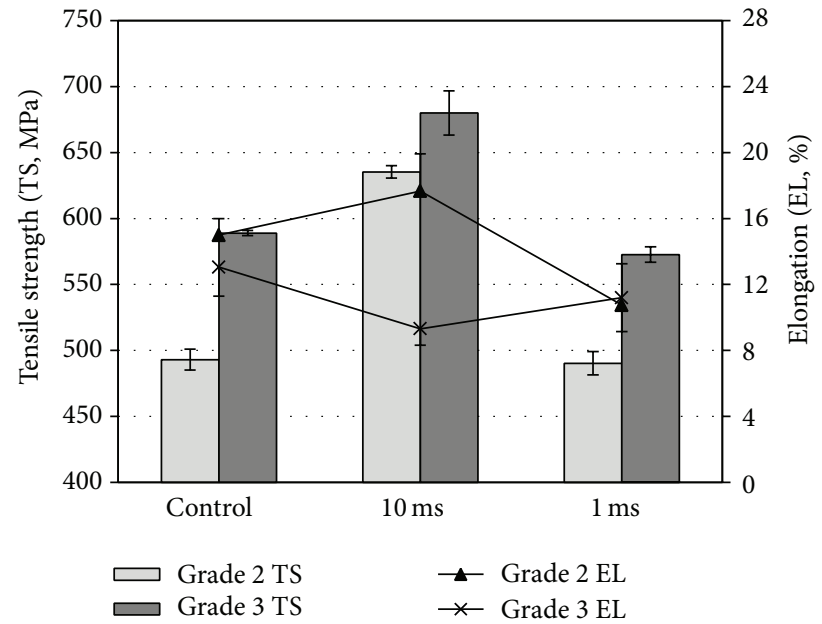

Figure 6: Tensile strengths and elongations of control specimens (grades 2 and 3) and specimens laser-treated with two different pulse durations (10 ms and $1 \mathrm{~ms})$ at a constant emission current $(220 \mathrm{~A})$ and a spot diameter $(1.0 \mathrm{~mm})$.

When two different pulse durations $(10 \mathrm{~ms}$ and $1 \mathrm{~ms})$ are applied to treat the pure titanium at a constant current of $220 \mathrm{~A}$ and a spot diameter of $1.0 \mathrm{~mm}$, the specimens treated with $10 \mathrm{~ms}$ pulse duration showed increased tensile strength compared to the control specimens, whereas the specimens laser-treated with $1 \mathrm{~ms}$ pulse duration showed lower tensile strength than the control specimens. The results of elongation demonstrated the results similar to those obtained in Figure 4 for testing of different spot diameters at a constant current $(200 \mathrm{~A})$ and pulse duration $(10 \mathrm{~ms})$.

3.2. Hardness Depth Profile. The hardness depth profiles obtained from cross-sections of control specimens and specimens laser-treated with various parameters are shown in

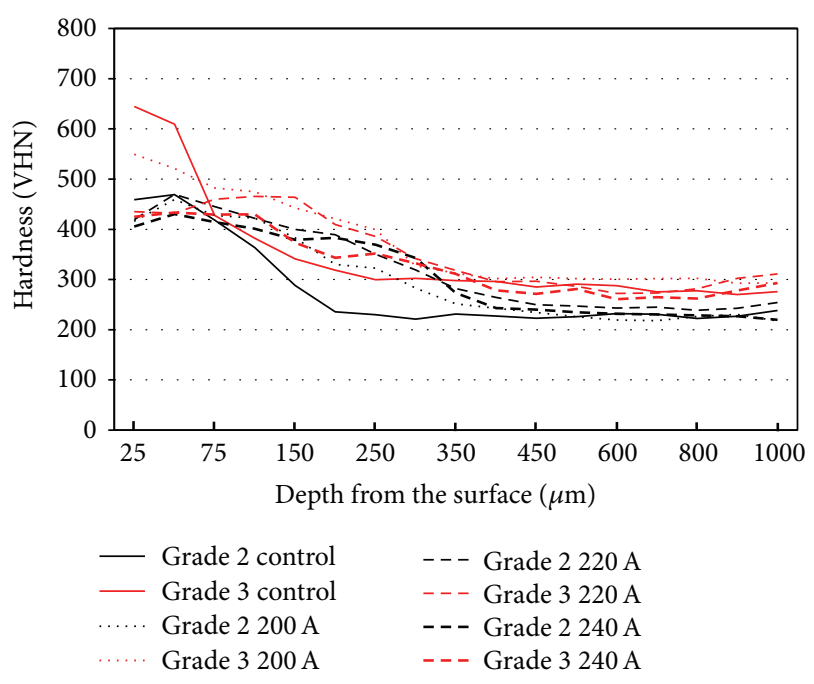

FIGURE 7: Hardness depth profiles from cast surface for control specimens (grade 2: black solid line, grade 3: red solid line) and specimens laser-treated with several emission currents $(200 \mathrm{~A}$, $220 \mathrm{~A}$, and $240 \mathrm{~A})$ at a constant pulse duration $(10 \mathrm{~ms})$ and a spot diameter $(1.0 \mathrm{~mm})$.

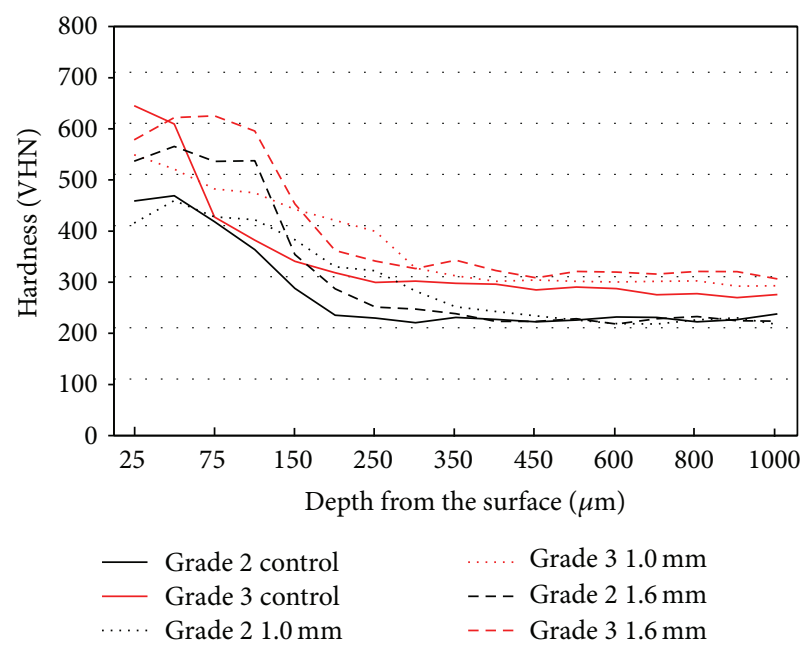

Figure 8: Hardness depth profiles from cast surface for control specimens (grade 2: black solid line, grade 3: red solid line) and specimens laser-treated with two different spot diameters $(1.0 \mathrm{~mm}$ and $1.6 \mathrm{~mm}$ ) at a constant emission current of $200 \mathrm{~A}$ and a pulse duration $(10 \mathrm{~ms})$.

Figures 7, 8, 9, and 10. Figure 7 demonstrates the hardness depth profiles for the specimens laser-treated with three different currents. The control specimens possess very high hardness at subsurface $(25 \mu \mathrm{m}$ and $50 \mu \mathrm{m})$ area on cross section. The laser treatment decreased the subsurface hardness and increased the hardness between $75 \mu \mathrm{m}$ and $400 \mu \mathrm{m}$ in depth when compared to the hardness of control specimens. Bulk hardness ( $>400 \mu \mathrm{m}$ in depth) is similar for all conditions (control specimens and specimens treated in all currents) in each grade of Ti. Note that the bulk hardness of grade 3 (red lines) is higher than those of grade 2 (black lines) at area 


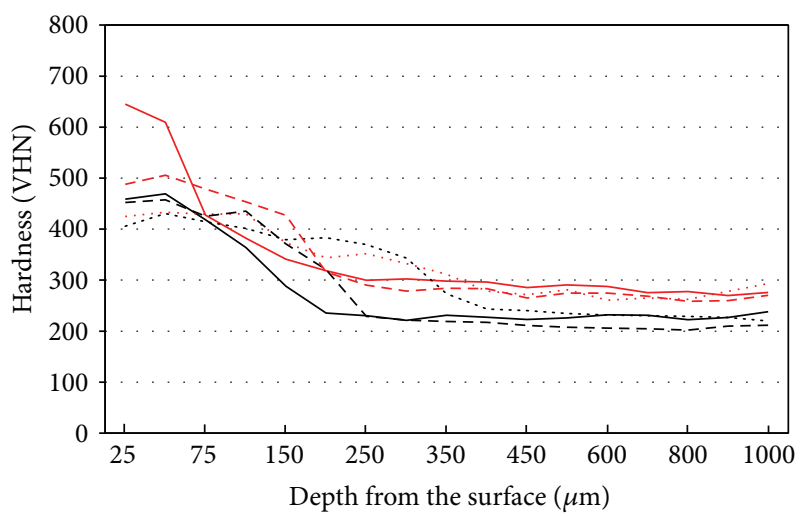

$$
\begin{array}{ll}
\text { — Grade } 2 \text { control } & \ldots . . \text { Grade } 31.0 \mathrm{~mm} \\
- \text { Grade } 3 \text { control } & --- \text { Grade } 21.6 \mathrm{~mm} \\
\cdots . . \text { Grade } 21.0 \mathrm{~mm} & --- \text { Grade } 31.6 \mathrm{~mm}
\end{array}
$$

Figure 9: Hardness depth profiles from cast surface for control specimens (grade 2: black solid line, grade 3: red solid line) and specimens laser-treated with two different spot diameters $(1.0 \mathrm{~mm}$ and $1.6 \mathrm{~mm}$ ) at a constant emission current of $240 \mathrm{~A}$ and a pulse duration (10 ms).

deeper than $400 \mu \mathrm{m}$. Hardness depth profiles of the specimens treated with two different spot diameters and constant pulse duration $(10 \mathrm{~ms}$ ) are presented in Figure 8 (constant current at $200 \mathrm{~A}$ ) and Figure 9 (constant current at $240 \mathrm{~A}$ ), respectively. Higher subsurface hardness between 25 and $150 \mu \mathrm{m}$ was obtained with lower current (200 A) and larger spot diameter $(1.6 \mathrm{~mm})$. The depth of the laser-affected area with high hardness increased as the spot diameter decreased and as the current increased (Figures 8 and 9). Figure 10 presents the hardness depth profiles of specimens treated with two different pulse durations with constant current $(220 \mathrm{~A})$ and spot diameter $(1.0 \mathrm{~mm})$. Subsurface hardness at $25 \mu \mathrm{m}$ of specimens treated with $1 \mathrm{~ms}$ pulse duration was higher than those of control specimens for both Ti grades, and the higher hardness was maintained until $150 \mu \mathrm{m}$ in depth. When the $10 \mathrm{~ms}$ of pulse was used to treat both grades of $\mathrm{Ti}$, subsurface hardness at $25 \mu \mathrm{m}$ of treated specimens was lower than those of control specimens. However the subsurface hardness with high hardness was maintained until $350 \mu \mathrm{m}$ in depth.

3.3. SEM Observation of Fracture Surfaces. The fracture surfaces observed after tensile testing are demonstrated in Figure 11. The subsurface area (a2) of control specimen (a1) had the cleavage acicular fractures which are typical microstructure of fractured cast pure titanium due to the surface reaction layer between the investment and molten titanium during casting. On the other hand, the laser-treated specimen (b1) showed a frat fracture surface at subsurface (lasertreated) area (b2).

\section{Discussion}

The laser surface treatment applied in this study apparently modified surface quality and resulted in increased mechanical strength (Figures 3 through 7). Cast pure titanium

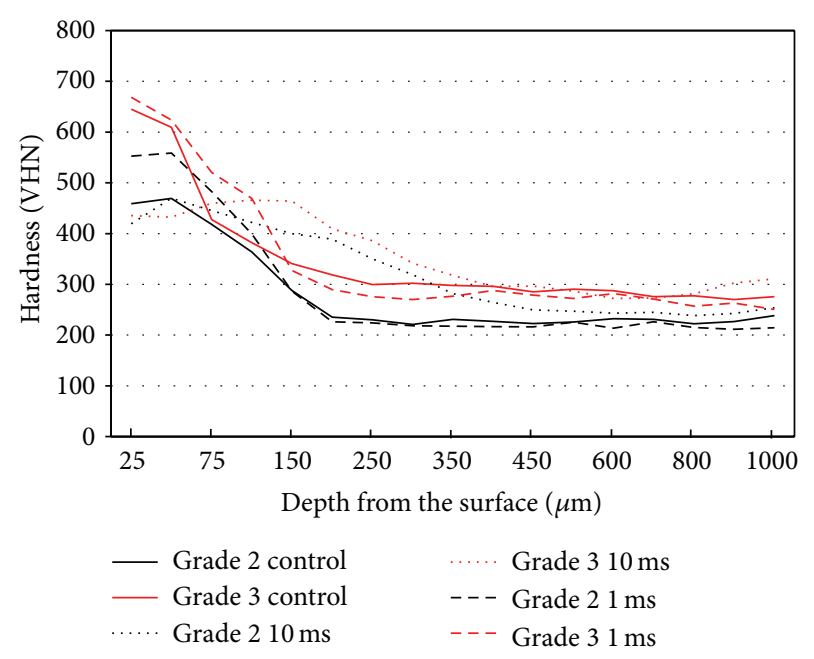

Figure 10: Hardness depth profiles from cast surface for control specimens (grade 2: black solid line, grade 3: red solid line) and specimens laser-treated with two different pulse durations $(10 \mathrm{~ms}$ and $1 \mathrm{~ms})$ at a constant emission current $(220 \mathrm{~A})$ and a spot diameter $(1.0 \mathrm{~mm})$.

normally produces hard and brittle cast surfaces generated by the reaction between investment material and molten titanium during casting as observed in Figure 7 and Figure 11. Note that the control specimens showed very high hardness at subsurface $(25 \mu \mathrm{m}$ and $50 \mu \mathrm{m})$ area on cross section (Figure 7) and fractured in brittle manner with cleavage acicular fracture (Figure 11(a2)). The thickness of surface reaction layer depends on the investment material used and casting conditions including atmosphere in casting unit and casting method (pressure type of machine, centrifugal machine). The thickness of cast metal frameworks also affects the thickness of surface reaction layer (thicker framework tends to thicken the reaction layer). In this study, the thickness of reaction layer could be estimated approximately 150$200 \mu \mathrm{m}$ in depth from the hardness depth profiles of control specimens (Figure 7). The laser surface treatment decreased subsurface hardness of the reaction layer and decreased hardness maintained beyond the reaction layer up to 350$400 \mu \mathrm{m}$ in depth (bulk hardness starts around this point). These hardness changes along with modification of subsurface microstructures (Figure 11) by laser treatment (Figure 11) resulted in improvement of mechanical properties. Another reason for improvement of mechanical properties might be due to the residual compressive stress of specimen surface induced by laser treatment. The laser can quickly melt and solidify the surface and the quick solidification introduced the residual stress on the surfaces.

Increasing of current up to $220 \mathrm{~A}$ significantly increased the tensile strength of laser-treated specimens for both $\mathrm{Ti}$ grades (Figure 3 ). However there are no statistical differences in tensile strength between $220 \mathrm{~A}$ and $240 \mathrm{~A}$ for both $\mathrm{Ti}$ grades. The reason might be the similar laser penetrations depth into the specimens between currents $220 \mathrm{~A}$ and $240 \mathrm{~A}$ as hardness depth profiles for grade $2 \mathrm{Ti}$ show similar behavior for these conditions (Figure 7). When the specimens 


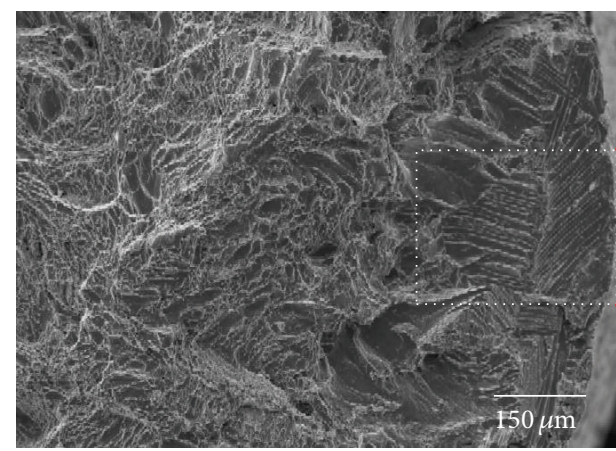

(a1)

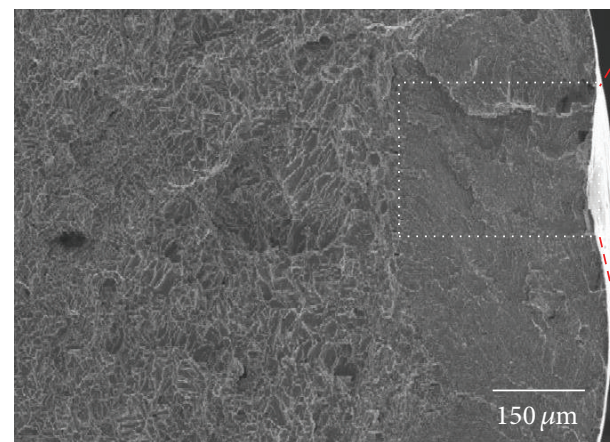

(b1)

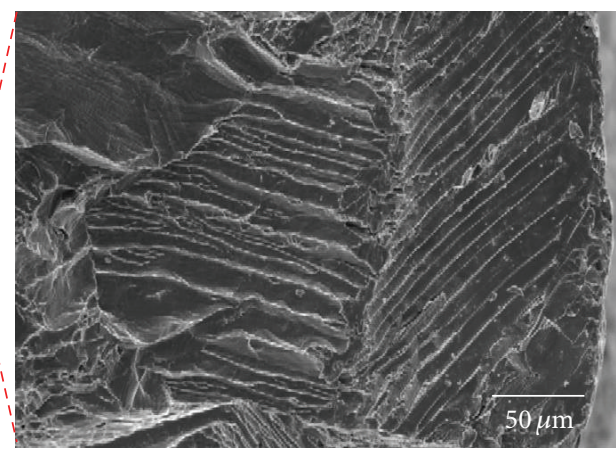

(a2)

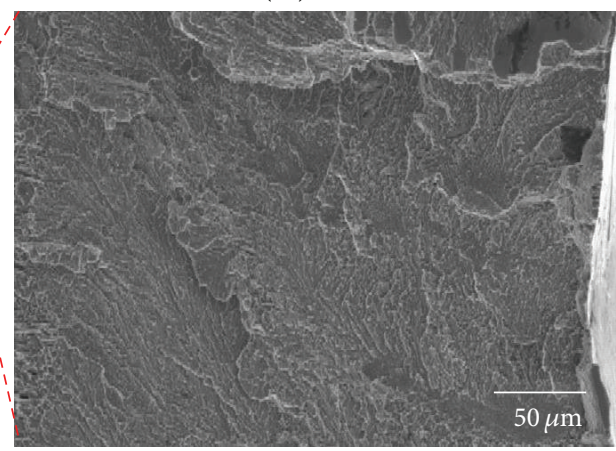

(b2)

FIGURE 11: Fracture surfaces after tensile testing. (a1) Grade 2 control specimen and (a2) magnified image from dotted square (subsurface area) in (al). (b1) Laser-treated grade 2 Ti specimen (current: $220 \mathrm{~A}$, pulse: $10 \mathrm{~ms}$, and spot diameter: $1.0 \mathrm{~mm}$ ) and (b2) magnified image from dotted square (laser-treated area) in (b1).

were laser-treated with two different spot diameters $(1.0 \mathrm{~mm}$ and $1.6 \mathrm{~mm})$, the results of tensile test were similar between $200 \mathrm{~A}$ (Figure 4) and $240 \mathrm{~A}$ (Figure 5); that is, higher tensile strengths were obtained for specimens treated with spot diameter of $1.0 \mathrm{~mm}$ than those treated with spot diameter of $1.6 \mathrm{~mm}$. The tensile strengths of the specimens laser-treated with 240 A (Figure 5) were slightly higher than those lasertreated with $200 \mathrm{~A}$ (Figure 4) in each corresponding condition (spot diameter and Ti grade). A laser with parameters such as small spot diameter and high current (high laser energy) can penetrate into metal surface deeper than a laser with large spot diameter and low current (low laser energy). The statement above can be confirmed by hardness depth profiles for both currents of $200 \mathrm{~A}$ (Figure 8) and $240 \mathrm{~A}$ (Figure 9). The tensile strengths of the specimens treated with small spot diameter $(1 \mathrm{~mm})$ were higher than those lasertreated with large spot diameter $(1.6 \mathrm{~mm})$. Another reason for this can be the number of laser treatment spots on the surface which simply increased to cover all interacted area. A large number of laser spots increase residual stress on the surface and resulted in improved mechanical strength. Figure 6 demonstrates the effect of pulse duration on tensile strength of surface treated Ti specimens. The specimens lasertreated with $1 \mathrm{~ms}$ pulse duration had lower tensile strength than those of the control specimens for both $\mathrm{Ti}$ grades. It is interesting that the subsurface hardness of specimens laser-treated with $1 \mathrm{~ms}$ pulse duration was higher than those of control specimens for both Ti grades. The high subsurface hardness indicates that the laser-surface treatment with $1 \mathrm{~ms}$ pulse duration increased brittleness of the surfaces and resulted in reduction of tensile strength for laser-treated specimens.

\section{Conclusions}

Laser surface treatment for cast commercially pure titanium modified integrity of cast surface and significantly improved mechanical property. From the results obtained in this study, the following conclusions can be drawn.

(1) Surface treatment by laser with higher currents (high laser energy) increased the tensile strength of the laser-treated specimens up to $220 \mathrm{~A}$ for both $\mathrm{Ti}$ grades.

(2) Tensile strengths of the specimens laser-treated with small spot diameter were higher than those lasertreated with large spot diameter for laser treatment for both Ti grades.

(3) The specimens laser-treated with $1 \mathrm{~ms}$ pulse duration had lower tensile strength than those of the control specimens for both Ti grades due to the top surface thinner hardening compared to $10 \mathrm{~ms}$ pulse duration. 


\section{Conflict of Interests}

The authors declare that there is no conflict of interests regarding the publication of this paper.

\section{References}

[1] B. Möller, H. Terheyden, Y. Ail et al., "A comparison of biocompatibility and osseointegration of ceramic and titanium implants: an in vivo and in vitro study," International Journal of Oral and Maxillofacial Surgery, vol. 41, no. 5, pp. 638-645, 2012.

[2] I. M. Shapiro, N. J. Hickok, J. Parvizi, S. Stewart, and T. P. Schaer, "Molecular engineering of an orthopaedic implant: from bench to bedside," European Cells and Materials, vol. 23, pp. 362-370, 2012.

[3] M. Abdel-Hady Gepreel and M. Niinomi, "Biocompatibility of Ti-alloys for long-term implantation," Journal of the Mechanical Behavior of Biomedical Materials, vol. 20, pp. 407-415, 2013.

[4] J. Yamazoe, M. Nakagawa, Y. Matono, A. Takeuchi, and K. Ishikawa, "The development of Ti alloys for dental implant with high corrosion resistance and mechanical strength," Dental Materials Journal, vol. 26, no. 2, pp. 260-267, 2007.

[5] Z. Cai, T. Shafer, I. Watanabe, M. E. Nunn, and T. Okabe, "Electrochemical characterization of cast titanium alloys," Biomaterials, vol. 24, no. 2, pp. 213-218, 2003.

[6] I. V. Okulov, S. Pauly, U. Kühn et al., "Effect of microstructure on the mechanical properties of as-cast $\mathrm{Ti}-\mathrm{Nb}-\mathrm{Al}-\mathrm{Cu}-\mathrm{Ni}$ alloys for biomedical application," Materials Science and Engineering: C, vol. 33, no. 8, pp. 4795-4801, 2013.

[7] B. Piotrowski, A. A. Baptista, E. Patoor, P. Bravetti, A. Eberhardt, and P. Laheurte, "Interaction of bone-dental implant with new ultra low modulus alloy using a numerical approach," Materials Science and Engineering C, vol. 38, no. 1, pp. 151-160, 2014.

[8] D. M. Brunette, P. Tengvall, M. Textor, and P. Thomsen, Titanium in Medicine-Materials Science, Surface Science, Engineering, Biological Responses and Medical Applications, Springer, New York, NY, USA, 2001.

[9] G. C. Stevenson and M. E. Connelly, "Titanium palate maxillary overdenture: a clinical report," Journal of Prosthodontics, vol. 1, no. 1, pp. 57-60, 1992.

[10] L. B. Helldén and T. Dérand, "Description and evaluation of asimplified method to achieve passive fit between cast titanium frameworks and implants," International Journal of Oral and Maxillofacial Implants, vol. 13, no. 2, pp. 190-196, 1998.

[11] C. Ohkubo, K. S. Kurtz, Y. Suzuki, S. Hanatani, M. Abe, and T. Hosoi, "Comparative study of maxillary complete dentures constructed of metal base and metal structure framework," Journal of Oral Rehabilitation, vol. 28, no. 2, pp. 149-156, 2001.

[12] C. Knabe and B. Hoffmeister, "Implant-supported titanium prostheses following augmentation procedures: a clinical report," Australian Dental Journal, vol. 48, no. 1, pp. 55-60, 2003.

[13] S. Guttal and N. P. Patil, "Cast titanium overlay denture for a geriatric patient with a reduced vertical dimension," Gerodontology., vol. 22, no. 4, pp. 242-245, 2005.

[14] K. A. Al Wazzan and A. A. Al-Nazzawi, "Marginal and internal adaptation of commercially pure titanium and titaniumaluminum-vanadium alloy cast restorations," Journal of Contemporary Dental Practice, vol. 8, no. 1, pp. 19-26, 2007.

[15] M. Koike, S. K. Hummel, J. D. Ball, and T. Okabe, "Fabrication of titanium removable dental prosthesis frameworks with a 2-step investment coating method," Journal of Prosthetic Dentistry, vol. 107, no. 6, pp. 393-399, 2012.
[16] I. Watanabe, J. H. Watkins, H. Nakajima, M. Atsuta, and T. Okabe, "Effect of pressure difference on the quality of titanium casting," Journal of Dental Research, vol. 76, no. 3, pp. 773-779, 1997.

[17] K. Iiyama, H. Doi, and T. Hanawa, "Effect of mold temperature on the mechanical durability of titanium casting clasp model," Dental Materials Journal, vol. 28, no. 5, pp. 610-619, 2009.

[18] C. Ohkubo, I. Shimura, T. Aoki, S. Hanatani, T. Hosoi, and T. Okabe, "In vitro wear assessment of titanium alloy teeth," Journal of Prosthodontics, vol. 11, no. 4, pp. 263-269, 2002.

[19] R. R. Rego, J. O. Gomes, and A. M. Barros, "The influence on gear surface properties using shot peening with a bimodal media size distribution," Journal of Materials Processing Technology, vol. 213, no. 12, pp. 2152-2162, 2013.

[20] J. Kritzler and W. Wubbenhorst, "Inducing compressive stresses through controlled shot peening," in Handbook of Residual Stress and Steel Deformation, pp. 345-358, ASM, Materials Park, Ohio, USA, 2002.

[21] A. Azhari, C. Schindler, E. Kerscher, and P. Grad, "Improving surface hardness of austenitic stainless steel using waterjet peening process," The International Journal of Advanced Manufacturing Technology, vol. 63, no. 9-12, pp. 1035-1046, 2012.

[22] C. Langlade, A. B. Vannes, J. M. Krafft, and J. R. Martin, "Surface modification and tribological behaviour of titanium and titanium alloys after YAG-laser treatments," Surface and Coatings Technology, vol. 100-101, no. 1-3, pp. 383-387, 1998.

[23] E. Richter, J. Piekoszewski, E. Wieser et al., "Modification of titanium surface by its alloying with silicon using intense pulsed plasma beams," Surface and Coatings Technology, vol. 158-159, pp. 324-327, 2002.

[24] E. György, A. P. Pdel Pino, P. Serra, and J. L. Morenza, "Influence of the ambient gas in laser structuring of the titanium surface," Surface and Coatings Technology, vol. 187, no. 2-3, pp. 245-249, 2004.

[25] Y. S. Tian, C. Z. Chen, S. T. Li, and Q. H. Huo, "Research progress on laser surface modification of titanium alloys," Applied Surface Science, vol. 242, no. 1-2, pp. 177-184, 2005.

[26] F. J. C. Braga, R. F. C. Marques, E. D. A. Filho, and A. C. Guastaldi, "Surface modification of Ti dental implants by Nd: $\mathrm{YVO}_{4}$ laser irradiation," Applied Surface Science, vol. 253, no. 23, pp. 9203-9208, 2007.

[27] L. Lavisse, J. M. Jouvard, J. P. Gallien, P. Berger, D. Grevey, and P. Naudy, "The influence of laser power and repetition rate on oxygen and nitrogen insertion into titanium using pulsed Nd:YAG laser irradiation," Applied Surface Science, vol. 254, no. 4, pp. 916-920, 2007.

[28] G. X. Luo, G. Q. Wu, Z. Huang, and Z. J. Ruan, "Microstructure transformations of laser-surface-melted near-alpha titanium alloy," Materials Characterization, vol. 60, no. 6, pp. 525-529, 2009.

[29] K. Mahmood, N. Farid, I. M. Ghauri, N. Afzal, Y. Idrees, and F. E. Mubarik, "Effects of laser irradiation on the mechanical response of polycrystalline titanium," Physica Scripta, vol. 82, no. 4, Article ID 045606, 6 pages, 2010.

[30] C. Bertrand and A. Poulon-Quintin, "Proposals for optimization of laser welding in prosthetic dentistry," Journal of Prosthodontics, vol. 19, no. 1, pp. 69-76, 2010.

[31] A. P. del Pino, P. Serra, and J. L. Morenza, "Laser surface processing of titanium in air: influence of scan traces overlapping," Journal of Laser Applications, vol. 15, no. 2, pp. 120-123, 2003. 
[32] L. Lavisse, M. C. Sahour, J. M. Jouvard et al., "Growth of titanium oxynitride layers by short pulsed Nd:YAG laser treatment of Ti plates: influence of the cumulated laser fluence," Applied Surface Science, vol. 255, no. 10, pp. 5515-5518, 2009.

[33] I. Watanabe, M. McBride, P. Newton, and K. S. Kurtz, "Laser surface treatment to improve mechanical properties of cast titanium," Dental Materials, vol. 25, no. 5, pp. 629-633, 2009.

[34] A. Poulon-Quintin, I. Watanabe, E. Watanabe, and C. Bertrand, "Microstructure and mechanical properties of surface treated cast titanium with Nd:YAG laser," Dental Materials, vol. 28, no. 9, pp. 945-951, 2012.

[35] J. Liu, I. Watanabe, K. Yoshida, and M. Atsuta, "Joint strength of laser-welded titanium," Dental Materials, vol. 18, no. 2, pp. 143-148, 2002. 

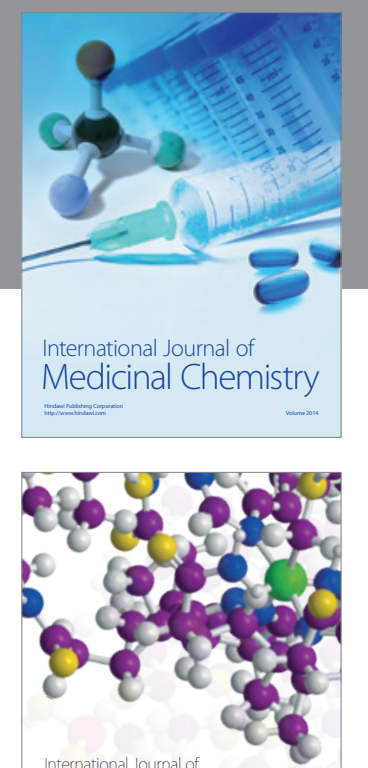

\section{Carbohydrate} Chemistry

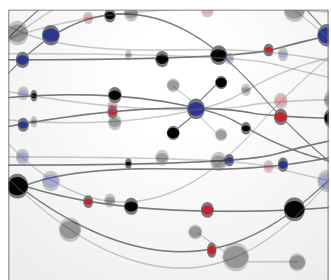

The Scientific World Journal
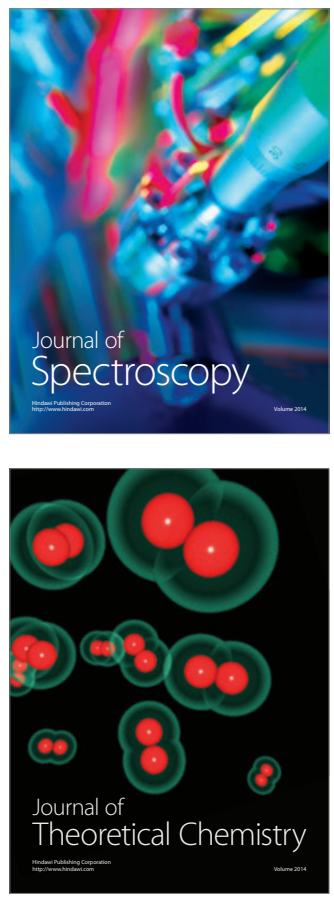
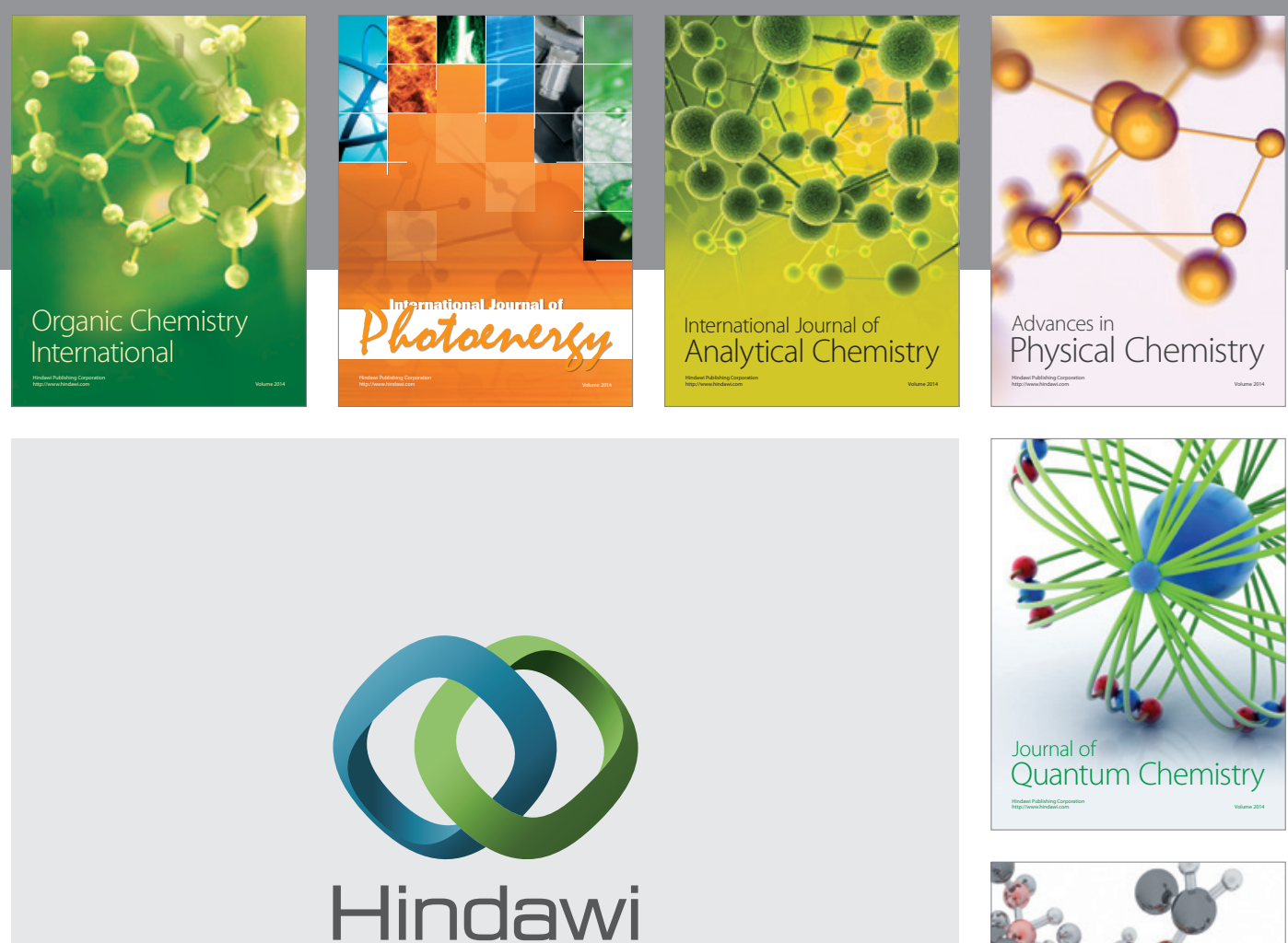

Submit your manuscripts at

http://www.hindawi.com

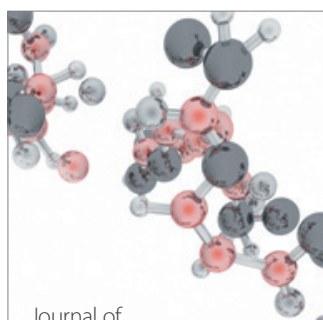

Analytical Methods

in Chemistry

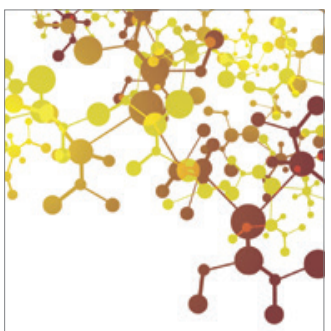

Journal of

Applied Chemistry

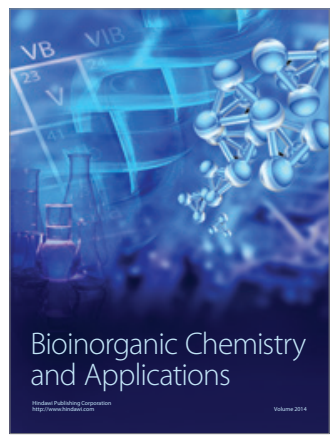

Inorganic Chemistry
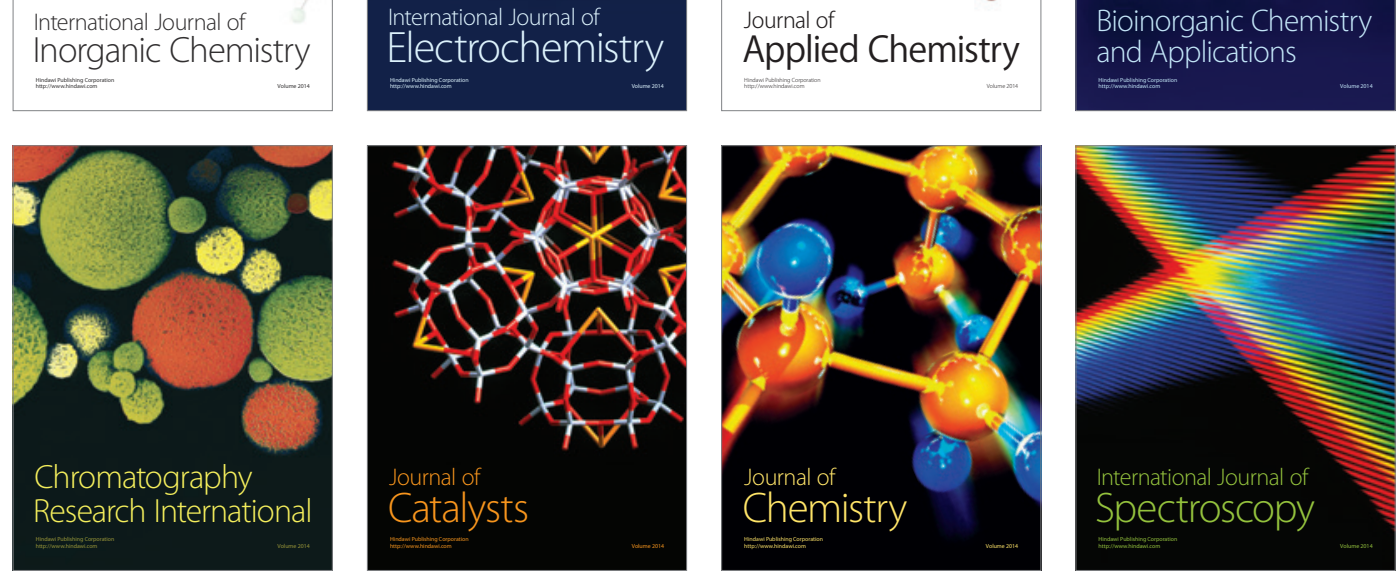